\title{
Peran Orang Tua dalam Pembelajaran Daring pada Masa Pandemi Melalui Aplikasi Groogle Classroom
}

\section{Wisnu Ferditama ${ }^{1^{*}}$, Sumarwiyah ${ }^{2}$ M. Syaffruddin $\mathbf{K}^{\mathbf{3}}$}

1,2,3Program StudiPendidikan Guru Sekolah Dasar, Universitas Muria Kudus, Kudus, Indonesia

\section{A R T I C L E I N F O}

Article history:

Received August 03, 2021

Revised August 07, 2021

Accepted September 30, 2021

Available online October 25, 2021

Kata Kunci:

Daring, Google Class room, peran orang tua

Keywords:

Online, Google Class room, role of parents

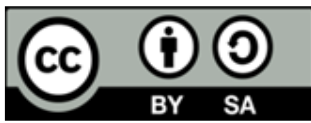

This is an open access article under the CC BY-SA license.

Copyright (@) 2021 by Author. Published by Universitas Pendidikan Ganesha.

\begin{abstract}
A B S T R A K
Peran orang tua dalam proses pembelajaran daring sangatlah dibutuhkan untuk memaksimalkan proses belajar mengajar. Penelitian ini bertujuan untuk mengetahui peran orang tua pada pembelajaran daring melalui aplikasi google classroom pada masa pandemi. Penelitian ini tergolong ke dalam jenis penelitian deskriptif kualitatif. Subjek yang telibat dalam penelitian ini yakni siswa kelas IV sekolah dasar, orang tua siswa, serta satu orang guru. Pengumpulan data dalam penelitian dilakukan dengan menggunakan metode observasi, wawancara, dan dokumentasi. Data yang diperoleh dalam penelitian kemudian dianalisis dengan menggunakan teknik analisis deskriptif kualitatif, yakni dengan cara menjabarkan hasil penelitian yang kemudian didukung oleh hasil penelitian terdahulu. Hasil penelitian menunjukkan bahwa dalam proses pembelajaran daring siswa sekolah dasar cenderung mengalami kendala dalam menggunakan aplikasi google clasroom serta mengalami kendala dalam memahami fitur-fitur yang telah tersedia di dalamnya. Upaya yang dapat dilakukan untuk mengatasi permasalahan tersebut yakni dengan memaksimalkan peran orang tua dalam kegiatan pembelajaran daring menggunakan google clasroom. Adapun peran orang tua dalam pembelajaran daring, yakni berperan sebagai guru dalam pembelajaran daring di rumah, berperan sebagai fasilitator, sebagai director, dan berperan sebagai motivator dalam pembelajaran daring dari rumah dan mampu membantu anak-anak dalam menyelesaikan kesulitan dalam pembelajaran daring di rumah menggunakan Google Classroom.
\end{abstract}

\section{A B S T R A C T}

The role of parents in the online learning process is needed to maximize the teaching and learning process. This research aims to determine the role of parents applied to online learning through the Google Classroom application during the pandemic. This research belongs to the type of qualitative descriptive research. The subjects involved in this study were fourth grade elementary school students, parents of students, and one teacher. Data collection in the study was carried out using the methods of observation, interviews, and documentation. The data obtained in the study were then analyzed using qualitative descriptive analysis techniques, namely by describing the results of the research which were then supported by the results of previous studies. The results showed that in the online learning process, elementary school students tend to experience problems using the Google Classroom application and have problems understanding the features that are available in it. Efforts that can be made to overcome these problems are by maximizing the role of parents in online learning activities using Google Classroom. The role of parents in learning is from acting as a teacher in online learning at home, acting as a facilitator, as a director, and acting as a motivator in online learning from home that is able to help children in solving forms of difficulties in online learning at home using Google Classroom.

\section{PENDAHULUAN}

Pelaksanaan pendidikan di Indonesia memiliki peran yang sangat strategis untuk meningkatkan sumber daya manusia dan upaya mewujudkan cita-cita bangsa Indonesia dalam mewujudkan kesejahteraan umum dan mencerdasakan kehidupan bangsa (Izma \& Kesuma, 2019; Kurniati et al., 2020). Sistem pendidikan nasional menjelaskan bahwa pendidikan nasional dilaksanakan untuk memenuhi 
tujuan pendidikan dan berfungsi untuk mengembangkan kemampuan dan membentuk watak serta peradaban bangsa yang bermartabat dalam rangka mencerdaskan kehidupan bangsa (Haerullah \& Eliham, 2020; Ilham, 2019; Suluh, 2018). Selain itu pelaksanaan pendidikan juga bertujuan untuk mengembangkan potensi peserta didik agar menjadi manusia yang beriman dan bertaqwa kepada Tuhan Yang Maha Esa, berakhlak mulia, sehat, berilmu, cakap, kreatif, mandiri dan menjadi warga negara yang demokratis serta bertanggung jawab (Sujana, 2019). Setiap masyarakat Indonesia diwajibkan untuk mengikuti proses pendidikan minimal selama 9 tahun. Melalui kegiatan belajar peserta didik akan mengalami perubahan tingkah laku ke arah yang lebih baik (Pane \& Dasopang, 2017). Perubahan ini didapat berupa penguasaan suatu kecakapan tertentu, perubahan sikap, memiliki ilmu pengetahuan yang berbeda dari sebelum seseorang melakukan proses pembelajaran. Kegiatan belajar dapat dilaksanakan di mana saja dan kapan saja, termasuk di masa pandemi seperti saat ini kegiatan belajar mengajar tetap harus dilaksanakan. Dalam masa darurat penyebaran covid-19, pelaksanaan pendidikan di Indonesia dilakukan melalui proses pembelajaran jarak jauh dengan memanfaatkan perkembangan teknologi yang ada (Fadhilaturrahmi et al., 2021; Salsabila et al., 2020). Pembelajaran jarak jauh disajikan melalui pembelajaran daring (dalam jaringan). Pembelajaran daring pada dasarnya merupakan kegiatan pembelajaran yang dilaksanakan dengan memanfaatkan teknologi pembelajaran, seperti google classroom, google meet, zoom, dll (Budiarti et al., 2021; Riyandi et al., 2020). Pembelajaran daring memungkinkan peserta didik dan guru belajar dalam kurun waktu yang bersamaan namun pada tempat yang berbeda. Selain itu, melalui pembelajaran daring, pelaksanaan pembelajaran dapat diselenggarakan secara massif dengan peserta yang tidak terbatas (Anugrahana, 2020; Asmuni, 2020).

Google classroom menjadi salah satu platform digital yang paling banyak banyak digunakan saat pembelajaran daring. Melalui google clasroom, siswa dan guru dapat melaksanakan pembelajaran seperti layaknya pembelajaran dalam kelas (Susanty, 2020). Google classroom menyediakan fitur ruang kelas. Guru dapat membentuk beberapa kelas dan mengelompokkan siswa berdasarkan kelasnya masingmasing (Marbun \& Sinaga, 2021; Misnan, 2021). Dalam ruang kelas yang telah disediakan, guru dapat mengirimkan materi dan melaksanakan diskusi bersama siswa (Harefa \& Sumiyati, 2020). Melalui google classroom guru juga dapat mencatat keaktifan serta partisipasi siswa dalam proses belajar (Misesani, 2021). Hanya saja pada pelaksanaannya masih terdapat beberapa kendala yang dirasakan oleh guru selama proses pembelajaran daring dengan menggunakan google classroom (Dewi \& Sadjiarto, 2021; Mahardini \& Mahitsa, 2020). Kendala yang paling banyak dirasakan, yakni siswa masih bingung dalam mengoprasikan dan memahaami materi yang disampaikan oleh guru melalui google classroom pada pembelajaran daring (Artatiningsih, 2021; Manurung et al., 2021). Hal ini sejalan dengan hasil observasi yang telah dilakukan di kelas IV di SD Negeri Sukokulon 01. Hasil observasi menunjukkan bahwa sebanyak 75\% siswa masih belum bisa berinteraksi dan menerima materi atau tugas yang diberikan guru melalui google claasroom. Siswa masih belum bisa memahami fitur-fitur yang terdapat pada google clasroom, seperti fitur kalender yang memuat tenggang waktu pengumpulan tugas yang membuat sisswa sering kali terlambat mengirimkan tugas karena beralasan tidak tahu. Siswa masih kesusahan dalam menemukan link daftar tugas apa saja yang harus dikerjakan siswa yang memyebabkan ketidak lengkapan tugas. Selain itu, siswa sering kali beralasan merasa susah dalam proses pengumpulan tugas karena kurang stabilnya signal yang digunakan yang mengakibatkan tugas tidak terkirim. Siswa sering kali lupa menandai tugas selesai yang mengakibatkan tugas siswa akan ditandai terlambat.

Berdasarkan permasalahan tersebut, orang tua mempunyai peran yang sangat penting dalam pendidikan anak-anak, terutama dalam proses pembelajaran. Orang tua harus mendampingi anak pada masa seperti ini yang mengharuskan anak-anak untuk belajar di rumah. Orang tua mempunyai kewajiban untuk memberikan motivasi dan semangat belajar bagi anak-anaknya agar anak dapat mengikuti pelajaran dengan baik dan efektif (Lilawati, 2020; Putro et al., 2020; Sari et al., 2021). Selain itu, orang tua juga berperan dalam memberikan fasilitas yang baik kepada anak. Ketika anak mengalami masalah dalam proses belajar, orang tua pula wajib memberikan solusi dan membantu anak agar tetap dapat mengikuti pembelajaran (Alexandro et al., 2021; Rahayu et al., 2021). Orang tua berperan penting dalam pendampingan proses belajar anak. Misalnya, ketika anak mengalami kesulitan dalam memahami materi, orang tua yang menjadi guru, yaitu membantu anak memahami materi pembelajaran yang anak belum memahami materi tersebut (Asmawati, 2021; Wajdi, 2021; Yulianingsih et al., 2020). Pendampingan menjadi sebuah upaya bantuan yang dilakukan pihak keluarga, khususnya orang tua dengan mendampingi anak untuk memenuhi kebutuhan dan pemecahan masalah anak dalam rangka mendukung optimalisasi perkembangan anak (Data et al., 2021).

Beberapa penelitian yang telah dilakukan sebelumnya mengungkapkan bahwa orang tua memiliki peran yang sangat besar dalam proses pembelajaran daring seperti berperan dalam pembentukan dan pembiasaan karakter anak, memberikan motivasi, menyediakan sarana dan prasarana penunjang proses pembelajaran, serta berperan dalam melakukan pengawasan dan bimbingan kepada anak saat 
pembelajaran daring (Istiadaningsih et al., 2021). Penelitian lainnya juga mengungkapkan hal serupa, yakni dalam proses pembelajaran daring orang tua memiliki peran untuk mendampingi anak agar anak merasa tidak sendiri, orang tua sebagai pemberi semangat, memfasilitasi kebutuhan anak, tempat berdiskusi dan bertanya, membantu mengenali diri sendiri, melihat dan mengembangkan bakat anak dan menciptakan lingkungan yang kondusif untuk belajar (Iftitah \& Anawaty, 2020). Hasil penelitian lainnya juga mengungkapkan bahwa orang tua memiliki peran untuk mendampingi proses pembelajaran secara penuh agar siswa dapat benar-benar belajar dan memahami apa yang sedang dipelajarinya (Cahyati \& Kusumah, 2020). Berdasarkan hasil penelitian sebelumnya dapat dikatakan bahwa dalam pembelajaran daring orang tua memiliki peran yang sangat besar untuk mendampingi serta mengawasi proses belajar anak. Hanya saja pada penelitian sebelumnya belum terdapat kajian mengenai peran orang tua dalam pembelajaran daring pada masa pandemi melalui aplikasi google classroom, khususnya pada siswa kelas IV SD. Oleh karena itu, penelitian ini difokuskan pada kajian tersebut dengan tujuan untuk mengetahui peran orang tua pada pembelajaran daring melalui aplikasi google classroom pada masa pandemi.

\section{METODE}

Penelitian ini tergolong ke dalam penelitian kualitatif deskriptif karena dilakukan dengan mengutamakan kedalaman penghayatan konsep yang dikaji secara empiris. Subjek yang terlibat dalam penelitian ini yakni siswa kelas IV SD Negeri Sukokulon 01, orang tua siswa, dan guru. Pengumpulan data dalam penelitian dilakukan dengan metode observasi, wawancara, dan dokumentasi. Instrumen yang digunakan yakni lembar observasi dan wawancara mengenai kendala serta peran orang tua dalam proses pembelajaran daring. Analisis data dalam penelitian dilakukan dengan menggunakan metode analisis deskriptif kualitatif yang terdiri dari proses pengumpulan data, reduksi data yang dilakukan dengan cara mengobrol dengan orang tua atau anak guna mendapatkan informasi yang lebih luas agar dapat menyelidiki data yang mungkin penting dan relevan yang erat kaitannya dengan penelitian yang dilakukan, serta display data (menampilkan data) yang dilakukan dengan penjabaran data yang diperoleh sebelumnya. Hasil wawancara dan observasi kemudian dijelaskan secara rinci agar mudah dibaca oleh orang lain, lalu verifikasi atau menyimpulkan hasil dalam bentuk laporan.

\section{HASIL DAN PEMBAHASAN}

Hasil

Berdasarkan hasil wawancara dan observasi didapatkan dua temuan dalam penelitian mengenai peran orang tua dalam pembelajaran daring pada masa pandemi melalui aplikasi google classroom. Temuan pertama berkaitan dengan kesulitan-kesulitan yang dialami oleh siswa dalam penggunaan google classroom. Dalam pembelajaran menggunakan google clasroom, siswa mengalami kesulitan sangat tinggi, karena tidak memahami materi pembelajaran yang disampaikan oleh guru secara daring, tidak bisa menerapkan konsep pembelajaran yang diberikan oleh guru dalam pembelajaran daring, kurang bisa menggunakan google clasroom sebagai media belajar dari rumah melalui daring, tidak bisa mengetahui fitur-fitur yang terdapat di google clasroom, kurang bisa melakukan interaksi tanya jawab melalui google clasroom, kurang bisa mengumpulkan tugas belajar dari rumah yang diterima melalui google clasroom.

Secara lebih rinci kesulitan-kesulitan belajar siswa selama proses pembelajaran menggunakan google classroom disajikan pada Tabel 1.

Tabel 1. Bentuk-bentuk Kesulitan dalam Penggunaan Google Classroom.

\begin{tabular}{|c|c|c|c|}
\hline No. & $\begin{array}{l}\text { Nama } \\
\text { Anak }\end{array}$ & $\begin{array}{c}\text { Nama Orang } \\
\text { Tua }\end{array}$ & Bentuk Kesulitan \\
\hline 1. & RA & Ibu DI & $\begin{array}{l}\text { a. Belum mengenal aplikasig google classrom. } \\
\text { b. Tidak mengetahui fungsi fitur yang ada di google classrom. } \\
\text { c. Google Classrom sering mengalami } \text { error }\end{array}$ \\
\hline 2. & DL & Ibu IK & $\begin{array}{l}\text { a. Tidak mengetahui fungsi fitur yang ada digGoogle classrom. } \\
\text { b. Google Classrom sering mengalami error. } \\
\text { c. Kesulitan dalam menemukan link tugas. } \\
\text { d. }\end{array}$ \\
\hline 3. & BT & Bapak RR & $\begin{array}{l}\text { a. Belum mengenal aplikasigGoogle classrom. } \\
\text { b. Google Classrom sering mengalami } \text { error. }\end{array}$ \\
\hline 4. & RO & Ibu FI & $\begin{array}{l}\text { a. Belum mengenal aplikasi google classrom. } \\
\text { b. Tidak mengetahui fungsi fitur yang ada di google classrom. }\end{array}$ \\
\hline
\end{tabular}




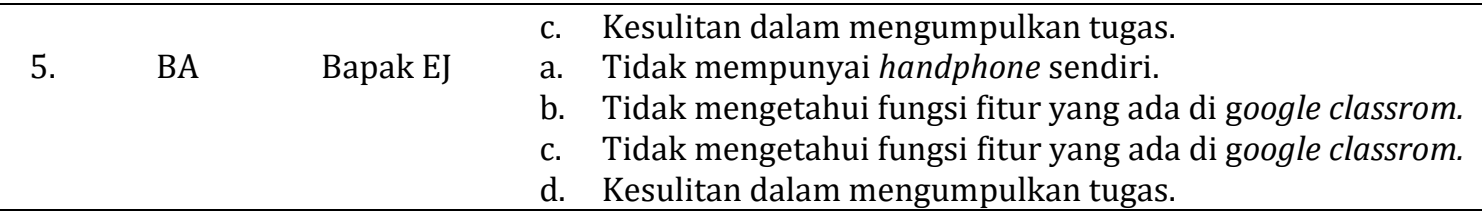

Temuan kedua dalam penelitian ini berkaitan dengan peran orang tua dalam penggunaan google clasroom. Hasil temuan kedua menunjukkan bahwa sebagian besar orang tua telah mampu melaksanakan perannya dengan baik, hanya saja masih terdapat beberapa peran yang tidak dapat dijalankan dengan baik. Dalam perannya sebagai pembimbing pembelajaran tiga dari lima orang tu siswa mengungkapkan bahwa mengalami kesulitan saat membantu menjelaskan materi ajar kepada anak. Orang tua cenderung kurang memahami materi ajar. Namun 2 orang tua lainnya yakni Bapak RR dan Ibu FI, dengan latar belakang pendidikan yang tinggi telah mampu melakukan perannya sebagai guru dalam membimbing anaknya belajar daring di rumah. Hal itu terlihat bahwa Bapak RR yang telaten dalam mengajari BT menggunakan google classroom. Tidak hanya itu, Bapak RR membantu menjelaskan materi yang diberikan guru melalui google classroom agar mudah dipahami oleh BT. Sejalan dengan hal tersebut, Ibu FI juga tekun dalam membimbing anak belajar daring di rumah. Ibu FI yang senantiasa mengajari RO mengoprasikan google classroom dan juga mengenalkan fungsi fitur-fitu yang ada di google classroom.

Selanjutnya dalam perannya untuk menyediakan sarana dan prasarana pembelajaran, orang tua telah mampu menyediakan sarana dan prasarana dengan baik. Hal itu terlihat dari Ibu DI yang mencukupi sarana belajar daring di rumah, yaitu menyediakan handphone dan paket data. Sama halnya dengan yang dilakukan Ibu IK, Bapak RR, Ibu FI, dan Bapak EJ yang memberikan handphone dan paket data atau Wi-Fi agar anak dapat mengikuti pembelajaran daring di rumah menggunakan google classroom. Pada perannya dalam melaksanakan strategi serta mengontrol proses belajar anak, orang tua telah mampu menerapkan strategi belajar dengan baik. Hal ini dapat dilihat dari Ibu DI yang memiliki strategi dalam menghadapi anak yang selalu mengeluh belajar daring di rumah yang terkesan membosankan. Ibu DI memberikan aturan-aturan di rumah atau mengancam tidak ada uang jajan kalau tidak mau belajar. Hal tersebut dilakukan Ibu DI agar anaknya bersemangat lagi belajar daring di rumah menggunakan google classroom. Sama halnya dengan Ibu IK, Bapak RR, Ibu FI, dan Bapak EJ yang memiliki strategi yang membuat anak semangat lagi belajar daring di rumah dengan cara memberikan aturan-aturan di rumah, seperti mendisiplinkan waktu belajar yang disesuaikan dengan waktu belajar saat ada di sekolah sampai pemberian apresiasi apabila anak berhasil mendapatkan nilai bagus.

Peran orang tua selanjutnya, yakni memberikan motivasi serta dorongan belajar kepada siswa. Hasil penelitian menunjukkan bahwa Ibu DI menyadari bahwa pentingnya pemberian dorongan atau motivasi terhadap anak dalam melaksanakan pembelajaran daring dari rumah. Motivasi yang diberikan Ibu DI ke anaknya adalah selalu memberi nasihat bawasannya meskipun di rumah tapi tetap belajar. Sama halnya dengan Ibu IK yang selalu memberikan motivasi kepada anaknya agar semangat belajar darng di rumah agar bisa meraih cia-cita. Sejalan dengan yang dilakukan Ibu IK, Ibu FI juga senantiasa memberikan motivasi jika anaknya mengeluh dalam melaksanakan pembelajaran daring dari dumah seperti mengingatkan cita-citanya agar giat lagi dalam belajar. Bapak RR yang memberikan pengertian dan dorongan bahwa pada kondisi apapun tugas anak memang harus belajar. Dan yang terakhir, Bapak EJ juga selalu memberikan dorongan atau motivasi dalam melaksanakan pembelajaran daring dari dumah seperti pemberian apresiasi terhadap anak.

\section{Pembahasan}

Hasil temuan pertama dalam penelitian menunjukkan bahwa sebagian besar siswa mengalami kesulitan dalam menggunakan aplikasi google clasroom. Hal ini disebabkan oleh kurangnya pemahaman siswa mengenai fungsi-fungsi fitur yang tersedia pada aplikasi google clasroom. Dalam kegiatan pembelajaran dari rumah, anak memang sering kali mengalami kesulitan dalam dalam mengoperasikan media pembelajaran online (Anugrahana, 2020; Asmuni, 2020; Manurung et al., 2021). Anak usia sekolah dasar masih kebingungan dalam mengoperasikan media pembelajaran online, apalagi saat diminta untuk melakukan pembelajaran seperti menerima materi dan tugas yang diberikan oleh guru (Arsy et al., 2021; Risalah et al., 2020). Kendala lain yang juga dirasakan siswa selama proses pembelajaran daring menggunakan google clasroom yakni handphone yang digunakan untuk belajar masih dimiliki orang tua yang mengakibatkan anak sering ketinggalan dalam belajar dan keterbatasan sinyal atau paket data ujga menyebabkan sering kali anak tidak bisa membuka googlecClassroom (Sarjono, 2021).

Dalam hal ini peran orang tua sangatlah dibutuhkan dalam menunjang proses pembelajaran daring anak. Hasil penelitian menunjukkan bahwa orang tua telah mampu menerapkan perannya dengan baik. Peran pertama yang telah diterapkan yakni orang tua telah mampu berperan sebagai guru dalam 
proses pembelajaran dari rumah (Huda \& Munastiwi, 2020; Lilawati, 2020; Wijayanti \& Fauziah, 2020). Hanya saja tidak semua orang tua mampu mengambil peran sebagai guru karena orang tua tidak dapat memahami materi pembelajaran anak-anaknya (Emiyati \& Harming, 2020; Rochmawati, 2018). Kurangnya kemampuan siswa dalam memahami materi yang diterima pada saat pembelajaran daring mengharuskan orang tua untuk mempelajari materi yang bukan bidangnya. Keterbatasan fasilitas terutama dalam hal kuota, pembagian waktu antara bekerja dan mendampingi anak selama pembelajaran daring, serta rumah yang bising karena banyak orang membuat anak susah berkonsentrasi ketika pembelajaran daring (Mahardini \& Mahitsa, 2020). Oleh karena itu, sebenarnya dalam hal ini peran guru sangat berarti dan tidak dapat tergantikan. Untuk mengatasi hal ini dibutuhkan kolaborasi antara orang tua dan guru untuk meningkatkan hasil belajar anak selama pembelajaran daring. Orang tua dan guru harus terlibat dalam membimbing anak selama pembelajaran daring.

Peran kedua yang telah dijalankan orang tua dalam proses pembelajaran daring menggunakan google clasroom, yakni menyediakan sarana dan prasarana (Fatonah \& Mulyono, 2021; Yuliantari, 2021). Sarana dan prasaran menjadi salah satu komponen penting dalam proses pembelajaran daring (Herlina, 2020; Salsabila et al., 2020). Dalam hal ini sarana yang paling dibutuhkan yakni hadphone serta paket data. Ketersediaan sarana dan prasarana yang memadai akan memudahkan proses belajar siswa (Wulandari et al., 2020). Peran orang tua yang ketiga yakni sabagai director dalam pembelajaran daring dari rumah menggunakan google classroom (Sari et al., 2021). Peran orang tua sebagai director merujuk kepada peran orang tua dalam menerapkan strategi pembelajaran yang baik untuk anak (Zahara et al., 2021). Kegiatan pembelajaran dari rumah tidak akan dapat berhasil tanpa adanya pengawasan dari orang tua. Berdasarkan hal tersebut, orang tua harus mampu menerapkan strategi pembelajaran yang baik, yang mampu meningkatkan hasil belajar serta minat belajar siswa. Peran orang tua yang kelima yakni menjadi motivator selama proses pembelajaran daring berlangsung. Pemberian motivasi dalam proses pembelajaran daring sangatlah dibutuhkan untuk meningkatkan minat belajar siswa (Hamida \& Putra, 2021; Wiradarma et al., 2021). Kegiatan pembelajaran daring yang dilakukan dari rumah cenderung menyebabkan kebosanan serta kejenuhan bagi siswa (Pawicara \& Conilie, 2020). Dalam pembelajaran daring, siswa sulit berinteraksi dengan guru dan teman-temannya. Peningkatan semangat belajar dapat dilakukan dengan memberikan dorongan serta dukungan belajar kepada anak agar anak senantiasa termotivasi dalam belajar, sehingga mampu meningkatkan hasil belajarnya (Ervalna et al., 2021; Fimala et al., 2021).

Hasil yang diperoleh dalam penelitian ini sejalan dengan hasil penelitian terdahulu yang juga mengungkapkan bahwa orang tua memiliki peran yang sangat besar dalam proses pembelajaran daring seperti berperan dalam pembentukan dan pembiasaan karakter anak, memberikan motivasi, menyediakan sarana dan prasarana penunjang proses pembelajaran serta berperan dalam melakukan pengawasan dan bimbingan kepada anak saat pembelajaran daring (Istiadaningsih et al., 2021). Penelitian lainnya juga mengungkapkan hal serupa, yakni dalam proses pembelajaran daring orang tua memiliki peran untuk mendampingi anak agar anak merasa tidak sendiri. Orang tua sebagai pemberi semangat, memfasilitasi kebutuhan anak, tempat berdiskusi dan bertanya, membantu mengenali diri sendiri, melihat dan mengembangkan bakat anak dan menciptakan lingkungan yang kondusif untuk belajar (Iftitah \& Anawaty, 2020). Hasil penelitian lainnya juga mengungkapkan bahwa orang tua memiliki peran untuk mendampingi proses pembelajaran secara penuh agar siswa dapat benar-benar belajar dan memahami apa yang sedang dipelajarinya (Cahyati \& Kusumah, 2020).

\section{SIMPULAN}

Simpulan yang dapat ditarik dari hasil penelitian ini. yakni dalam proses pembelajaran daring siswa sekolah dasar cenderung mengalami kendala dalam menggunakan aplikasi google clasroom serta mengalami kendala dalam memahami fitur-fitur yang telah tersedia di dalamnya. Upaya yang dapat dilakukan untuk mengatasi permasalahan tersebut, yakni dengan memaksimalkan peran orang tua dalam kegiatan pembelajaran daring menggunakan google clasroom. Adapun peran orang tua dalam pembelajaran daring, yakni berperan sebagai guru dalam pembelajaran daring di rumah, berperan sebagai fasilitator, sebagai director, dan berperan sebagai motivator dalam pembelajaran daring dari rumah, sehingga mampu membantu anak-anak dalam menyelesaikan kesulitan dalam pembelajaran daring di rumah menggunakan google classroom.

\section{DAFTAR RUJUKAN}

Alexandro, R., Putri, W. U., Hariatama, F., \& Oktaria, M. (2021). Peran Orang Tua dalam Meningkatkan Prestasi Belajar Siswa di SMA Negeri 2 Muara Teweh Kabupaten Barito Utara. Jurnal Pendidikan 
Ilmu Pengetahuan Sosial (JPIPS), 13(2), 92-108. https://e-journal.upr.ac.id/index.php/JPIPS/article/view/3717/2846.

Anugrahana, A. (2020). Hambatan, Solusi dan Harapan: Pembelajaran Daring Selama Masa Pandemi Covid-19 oleh Guru Sekolah Dasar. Scholaria: Jurnal Pendidikan Dan Kebudayaan, 10(3), 282-289. https://doi.org/10.24246/j.js.2020.v10.i3.p282-289.

Arsy, G. R., Listyarini, A. D., \& Nyumirah, S. (2021). Pendampingan Psikologis Orang Tua pada Anak Usia Sekolah selama Pembelajaran Daring. Jurnal Keperawatan Dan Kesehatan Masyarakat Cendekia Utama, 10(2), 161. https://doi.org/10.31596/jcu.v10i2.762.

Artatiningsih, A. (2021). Penerapan Aplikasi Google Classroom dalam Manajemen Pembelajaran Jarak Jauh di Sekolah Kejuruan. Media Manajemen Pendidikan, 4(1), 81-91. https://doi.org/10.30738/mmp.v4i1.8833.

Asmawati, L. (2021). Peran Orang Tua dalam Pemanfaatan Teknologi Digital pada Anak Usia Dini. Jurnal Obsesi : Jurnal Pendidikan Anak Usia Dini, 6(1), 82-96. https://doi.org/10.31004/obsesi.v6i1.1170.

Asmuni, A. (2020). Problematika Pembelajaran Daring di Masa Pandemi Covid-19 dan Solusi Pemecahannya. Jurnal Paedagogy, 7(4), 281-288. https://doi.org/10.33394/jp.v7i4.2941.

Budiarti, Marlinda Indah, Titing, T., \& Dhipanusa, K. (2021). Keefektifan Penggunaan Google Class Room dan Zoom selama Pandemi Covid 19 pada Pembelajaran Matematika. JPB : Jurnal Patria Bahari, 1(1), 9-23. https://doi.org/10.54017/jpb.v1i1.16.

Cahyati, N., \& Kusumah, R. (2020). The Role of Parents in Applying Learning at Home during the Covid Pandemic 19. Journal Golden Age, Universitas Hamzanwadi, 04(1), 4-6. https://ejournal.hamzanwadi.ac.id/index.php/jga/article/view/2203/1326.

Data, A. B., Talizaro Tafonao, Sidabutar, D. L., \& Rini Sumanti Sapalakkai. (2021). Peran Pendampingan Orang Tua dalam Pembelajaran Anak Usia Dini selama Belajar dari Rumah di Masa Pandemi Covid-19. ELEOS: Jurnal Teologi dan Pendidikan Agama Kristen, 1(1), 50-62. https://doi.org/10.53814/eleos.v1i1.5.

Dewi, T. A. P., \& Sadjiarto, A. (2021). Pelaksanaan Pembelajaran Daring pada Masa Pandemi Covid-19. Jurnal Basicedu, 5(4), 1909-1917. https://doi.org/10.31004/basicedu.v5i4.1094.

Emiyati, A., \& Harming. (2020). Kendala Orang Tua Mendampingi Anak Belajar di Rumah dalam Menghadapi Situasi Covid 19. Civic-Culture : Jurnal Ilmu Pendidikan PKN Dan Sosial Budaya, 4(1), 1-7. http://194.59.165.171/index.php/CC/article/view/336\%0A.

Ervalna, N. N., Rapani, R., \& Izzatika, A. (2021). Hubungan Peran Orang Tua dalam Pendampingan dan Motivasi Belajar dengan Hasil Belajar Anak di Era New Normal Pandemi Covid-19. Pedagogi: Jurnal Pendidikan Dasar, 9(1), 1-19. https://doi.org/10.23960/pdg.v9i1.23167.

Fadhilaturrahmi, F., Ananda, R., \& Yolanda, S. (2021). Persepsi Guru Sekolah Dasar terhadap Pembelajaran Jarak Jauh di Masa Pandemi Covid 19. Jurnal Basicedu, 5(3), 1683-1688. https://doi.org/10.31004/basicedu.v5i3.1187.

Fatonah, U., \& Mulyono, R. (2021). Manajemen E-Learning dalam Pembelajaran Jarak Jauh pada Masa Pandemi Covid-19. Media Manajemen Pendidikan, 4(1), 150-159. https://doi.org/10.30738/mmp.v4i1.9906.

Fimala, Y., S, N., \& Murni, I. (2021). Peran Orang Tua dan Guru dalam Memotivasi Peserta Didik Sekolah Dasar di Masa Pandemi. JPGI (Jurnal Penelitian Guru Indonesia), 6(1), 44. https://doi.org/10.29210/02927jpgi0005.

Haerullah, H., \& Eliham, E. (2020). Dimensi Perkembangan Pendidikan Formal dan Nonformal. Jurnal Edukasi Nonformal, 1(1). https://ummaspul.e-journal.id/JENFOL/article/view/504/293.

Hamida, S., \& Putra, E. D. (2021). Peran Orang Tua dalam Meningkatkan Motivasi Belajar Siswa di Masa Pandemi COVID-19. Mimbar Ilmu, 26(2), 302. https://doi.org/10.23887/mi.v26i3.39024.

Harefa, N., \& Sumiyati, S. (2020). Persepsi Siswa terhadap Google Classroom sebagai LMS pada masa Pandemi Covid-19. Science Education and Application Journal, 2(2), 88. https://doi.org/10.30736/seaj.v2i2.270.

Herlina, N. (2020). Manajemen Pembelajaran Daring di Perguruan Tinggi pada Masa Pandemi Covid-19. Journal Civics \& Social Studies, 4(2), 102-108. https://doi.org/10.31980/civicos.v4i2.925.

Huda, K., \& Munastiwi, E. (2020). Strategi Orang Tua dalam Mengembangkan Bakat dan Kreativitas Anak di Era Pandemi Covid-19. Jurnal Pendidikan Glasser, 4(2), 80. https://doi.org/10.32529/glasser.v4i2.670.

Iftitah, S. L., \& Anawaty, M. F. (2020). Peran Orang Tua dalam Mendampingi Anak di Rumah selama Pandemi Covid-19. JCE Journal of Childhood Education), 4(2), 71. https://doi.org/10.30736/jce.v4i2.256.

Ilham, D. (2019). Menggagas Pendidikan Nilai dalam Sistem Pendidikan Nasional. Didaktika: Jurnal 
Kependidikan, 8(3), 109-122. https://jurnaldidaktika.org/contents/article/view/73/55.

Istiadaningsih, D., Adisel, \& Fitriana, S. (2021). Peran Orang Tua dalam Menyukseskan Pembelajaran Daring pada Masa Pandemi Covid-19 di Kelas III SEKOLAH DASAR. Journal Of Elemantary School (JOES), 4(1), 6. https://doi.org/10.31539/joes.v4i1.2024.

Izma, T., \& Kesuma, V. Y. (2019). Peran Pendidikan Kewarganegaraan dalam Membangun Karakter Bangsa. Wahana Didaktika: Jurnal Ilmu Kependidikan, 17(1), 84. https://doi.org/10.31851/wahanadidaktika.v17i1.2419.

Kurniati, E., Alfaeni, D. K. N., \& Andriani, F. (2020). Analisis Peran Orang Tua dalam Mendampingi Anak di Masa Pandemi Covid-19. Jurnal Obsesi: Jurnal Pendidikan Anak Usia Dini, 5(1), 241. https://doi.org/10.31004/obsesi.v5i1.541.

Lilawati, A. (2020). Peran Orang Tua dalam Mendukung Kegiatan Pembelajaran di Rumah pada Masa Pandemi. Jurnal Obsesi: Jurnal Pendidikan Anak Usia Dini, 5(1), 549. https://doi.org/10.31004/obsesi.v5i1.630.

Mahardini, A., \& Mahitsa, M. (2020). Analisis Situasi Penggunaan Google Classroom pada Pembelajaran Daring Fisika. Jurnal Pendidikan Fisika, 8(2), 215. https://doi.org/10.24127/jpf.v8i2.3102.

Manurung, R., Sadjiarto, A., \& Sitorus, D. S. (2021). Aplikasi Google Classroom sebagai Media Pembelajaran Online dan Dampaknya terhadap Keaktifan Belajar Siswa pada Masa Pandemi Covid-19. Jurnal Hasil Penelitian Dan Kajian Kepustakaan Di Bidang Pendidikan, Pengajaran Dan Pembelajaran, 7(3), 729. https://doi.org/10.33394/jk.v7i3.3853.

Marbun, J., \& Sinaga, S. J. (2021). Pemanfaatan Aplikasi Google Classroom dalam Meningkatkan Efektivitas Belajar Mahasiswa Berbasis Daring di Masa Pandemik Covid-19. Jurnal Basicedu, 5(5), 32993305. https://doi.org/10.31004/basicedu.v5i5.1326.

Misesani, D. (2021). Peningkatan Kemampuan Guru dalam Pemanfaatan Google Classroom sebagai Media Pembelajaran Online. JMM Uurnal Masyarakat Madani), 5(4), 1640-1652. https://doi.org/10.31764/jmm.v5i4.5078.

Misnan. (2021). Analisis Pemanfaatan Google Classromm di Masa Pendemi C0vid-19. Edutech : Jurnal $\begin{array}{llll}\text { Inovasi Pendidikan } \quad \text { Berbantuan } & \text { 1(2), }\end{array}$ https://doi.org/10.51878/edutech.v1i2.408.

Pane, A., \& Dasopang, M. D. (2017). Belajar dan Pembelajaran. FITRAH:Jurnal Kajian Ilmu-Ilmu Keislaman, 3(2), 333. https://doi.org/10.24952/fitrah.v3i2.945.

Pawicara, R., \& Conilie, M. (2020). Analisis Pembelajaran Daring terhadap Kejenuhan Belajar Mahasiswa Tadris Biologi IAIN Jember di Tengah Pandemi Covid-19. ALVEOLI: Jurnal Pendidikan Biologi, 1(1), 29-38. https://doi.org/10.35719/alveoli.v1i1.7.

Putro, K. Z., Amri, M. A., Wulandari, N., \& Kurniawan, D. (2020). Pola Interaksi Anak dan Orangtua selama Kebijakan Pembelajaran di Rumah. Fitrah: Journal of Islamic Education, 1(1), 124-140. https://doi.org/10.53802/fitrah.v1i1.12.

Rahayu, P., Rohana, R., \& Febriani, E. (2021). Analisis Peran Orang Tua sebagai Pengganti Guru Sekolah di Masa Pandemi Covid-19 Siswa SMP Negeri 1 Panai Tengah Kabupaten Labuhanbatu. Jurnal Ilmiah Profesi Pendidikan, 6(1), 87-95. https://doi.org/10.29303/jipp.v6i1.157.

Risalah, A., Ibad, Maghfiroh, Azza, M. I., Cahyani, \& Ulfayati, Z. A. (2020). Dampak Pandemi Covid-19 terhadap Kegiatan Belajar Mengajar di MI/SD (Studi KBM Berbasis Daring bagi Guru dan Siswa. JIEES: Journal of Islamic Education at Elementary School, 1(1), 10-16. https://doi.org/10.47400/jiees.v1i1.5.

Riyandi, A., Aulianita, R., Wiyatno, A., Triantori, V., \& Musyaffa, N. (2020). Pemanfaatan Teknologi untuk Pembelajaran Jarak Jauh di Masa Pandemi Covid-19. Jurnal AbdiMas Nusa Mandiri, 2(2), 37-42. https://doi.org/10.33480/abdimas.v2i2.1682.

Rochmawati, N. (2018). Peran Guru dan Orang Tua Membentuk Karakter Jujur pada Anak. Jurnal Al-Fikri: Jurnal Studi Dan Penelitian Pendidikan Islam, 1(2), 1-12. http://lppmunissula.com/jurnal.unissula.ac.id/index.php/fikri/article/view/ 32032336.

Salsabila, U. H., Sari, L. I., Lathif, K. H., Lestari, A. P., \& Ayuning, A. (2020). Peran Teknologi dalam Pembelajaran di Masa Pandemi Covid-19. Al-Mutharahah: Jurnal Penelitian Dan Kajian Sosial Keagamaan, 17(2), 188-198. https://doi.org/10.46781/al-mutharahah.v17i2.138.

Sari, D. O., Drupadi, R., \& Syafrudin, U. (2021). Peran Orang Tua dalam Proses Penyesuaian Diri Anak Usia Dini terhadap Kegiatan Pembelajaran di Rumah. Jurnal Anak Usia Dini Dan Pendidikan Anak Usia Dini, 7(2), 149-160. https://doi.org/ 10.30651/pedagogi.v7i2.7001.

Sarjono, S. (2021). Penetrasi Google Classroom pada Siswa Sekolah Menengah Kejuruan pada Pembelajaran Daring di Era Pandemi. Edumaspul: Jurnal Pendidikan, 5(2), 424-434. https://doi.org/10.33487/edumaspul.v5i2.1914.

Sujana, I. W. C. (2019). Fungsi dan Tujuan Pendidikan Indonesia. Adi Widya: Jurnal Pendidikan Dasar, 4(1), 
29. https://doi.org/10.25078/aw.v4i1.927.

Suluh, M. (2018). Perspektif Pendidikan Nasional. Jurnal Penelitian dan Pengkajian Ilmu Pendidikan: ESaintika, 2(1), 1. https://doi.org/10.36312/e-saintika.v2i1.78.

Susanty, S. (2020). Inovasi Pembelajaran Daring dalam Merdeka Belajar. Jurnal Ilmiah Hospitality, 9(2), 157-166. https://doi.org/10.47492/jih.v9i2.289.

Wajdi, F. (2021). Manajemen Perkembangan Siswa SD melalui Peran Guru dan Orang Tua pada Masa

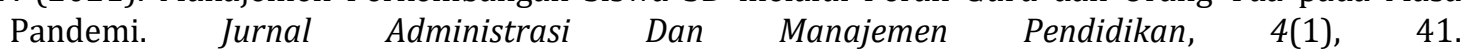
https://doi.org/10.17977/um027v4i12021p41.

Wijayanti, R. M., \& Fauziah, P. Y. (2020). Perspektif dan Peran Orang Tua dalam Program PJJ Masa Pandemi Covid-19 di PAUD. Jurnal Obsesi : Jurnal Pendidikan Anak Usia Dini, 5(2), 1304-1312. https://doi.org/10.31004/obsesi.v5i2.768.

Wiradarma, K. S., Suarni, N. K., \& Renda, N. T. (2021). Analisis Hubungan Minat Belajar terhadap Hasil Belajar Daring IPA Siswa Kelas III Sekolah Dasar. MIMBAR PGSD Undiksha, 3(7). https://doi.org/ 10.23887/jjpgsd.v9i3.39212.

Wulandari, M. A., Arga, H. S. P., \& Kelana, J. B. (2020). Analisis Pembelajaran "Daring” pada Guru Sekolah Dasar di Era Covid-19. Jurnal Ilmiah P2m Stkip Siliwangi, 7(2). https://doi.org/10.22460/p2m.v7i2p\%25p.2002.

Yulianingsih, W., Suhanadji, S., Nugroho, R., \& Mustakim, M. (2020). Keterlibatan Orang Tua dalam Pendampingan Belajar Anak selama Masa Pandemi Covid-19. Jurnal Obsesi : Jurnal Pendidikan Anak Usia Dini, 5(2), 1138-1150. https://doi.org/10.31004/obsesi.v5i2.740.

Yuliantari, A. P. (2021). Pendampingan Pembelajaran Daring terhadap Peserta Didik SMAK Setia Bakti Ruteng Masa Pandemi Covid 19. Randang Tana: Jurnal Pengabdian Kepada Masyarakat, 4(2), 1-9. https://doi.org/10.36928/jrt.v4i2.784.

Zahara, S., Mulyana, N., \& Darwis, R. S. (2021). Peran Orang Tua dalam Mendampingi Anak Menggunakan Media Sosial di Tengah Pandemi Covid-19. Jurnal Kolaborasi Resolusi Konflik, 3(1), 105. https://doi.org/10.24198/jkrk.v3i1.32143. 